1995119506

$5,5-93$

N95- 25926 ,

APPENDIX N

Linear Energy Transfer (LET) 8pectra of Cosmic Radiation in Low Earth Orbit by

A.B. Akopova, N.V. Magradze, V.E. Dudkin, E.E. Kovalev, Yu.V. Potapov, B.V. Benton, A.L. Frank, E.R. Benton T.A. Parnell and J.W. Watts, Jr.

(182) 
$=\overline{7}$

$+$ 


\title{
LINEAR ENERGY TRANSFER (LET) SPECTRA OF COSMIC RADIATION IN LOW EARTH ORBIT
}

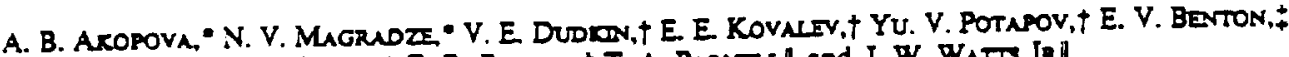 \\ A. L. Frunk, E R. Benton \pm T. A. PARneLI and J. W. WATts JRll \\ - Yerevan Institute of Physies, Yerevan. U.S.S.R. †'nstitute of Biomedical Problems of the Ministry of \\ Public Health of the U.S.S.R., Moseow 123007, U.S.S.R: tUniversity of San Franciseo, $\$$ CA 94117. \\ U.S.A. and INASA Marshall Spaceflight Center, Hustsville, AI 35812 U.S.A.
}

(Reczived 30 May 1989)

\begin{abstract}
Integral linear energy transfer (LET) spectra of cosmic radiation (CR) particles werc measured Absure Cosmos series spacecraft in low Earth orbit (LEO). Particular emphasis is placed on results of the Cosmos 1887 biosatellite which arried a set of joint U.S.S.R.-U.S.A. madiation experiments involving persive detectors that included thermoluminescent decectors (TLDs), plastic nuclear track desectors (PNIDs), fission foils, nuclear photo-emulsions, etc. which were located both inside and ourside the spacectaft. Measured LET spectra are compared with those theoretically alculated. Resuits show that there is some dependeace of LET spectra on orbital parameters. The results are used to estimate the CR quality factor (QF) for the Cosmos 1887 mission.
\end{abstract}

\section{INTRODUCTION}

THE INTEGRAI linear energy transfer (LET) spectra are important for characterizing cosmic radiation (CR) because they can be used to escimate the absorbed and equivalent particle dose and to evaluate the respective quality factors. Earlier, the integral LET distributions were measured in the following works: Petrov et al. (1975), Benton (1983, 1986), and Akopova et al. (1985, 1986, 1987, 1988). As a rule, these investigations used passive detectors (plates, emulsions) which permitted measurements in a restricted LET interval. In some investigations (e.g. Akopova ef al., 1987, 1988; Heinrich, 1977; Heinrich and Baer, 1984), the LET distributions were calculated as a function of shielding. In all of these theoretical studies, only the galactic cosmic ray particles were regarded as sources of cosmic radiation.

This paper presents the results of a recent experimental and calculational study carried out by the authors. Particular attention was paid to comparing results obtained by various experimental techniques, and to finding the laws which govern the dependence of the forms of the integral LET distributions on orbital parameters. Measurements were taken in free space (behind very thin shielding), and inside the spacecraft where the mean thickness of the shieiding of detectors reached tens of $\mathrm{g} \mathrm{cm}^{-2}$. The contribution of trapped protons and electrons is also taken into account in the theoretical calculations.

\section{EXPERIMENTAL TECHNTQUES}

The use of LET spectral data is necessary for appraising the radiation environment inside spacecraft. Previous measurements were made on board Cosmos 782, 936, and 1129 using an electron spectrometer, nuclear emulsions, and plastic detectors. These results have been presented by Benton (1986) together with dosimetric measurements and LET spectra obtained on board some of the U.S. Shuttle fights.

The current work presents the results obcained on board five Cosmos-type satelites using two types of detectors, namely, nuclear photo-emulsions (NPE) and solid stace nuclear track detectors (SSNTDs). The NPE assemblies concaining $200 \mu$ m thick BRand BYa-type emulsions wrapped with light-tight paper and aluminized Lavsan were placed either in instrument modules outside the spacecraft or inside the spacecraft. After exposure and recovery, each layer of emulsion assembly was treated by the selective-development technique which makes it possible to control the NPE layer threshold sensidivity in a broad interval of LET (see Akopova et al., 1983). The emulsion threshold sensitivity control is based on the introduction of $\mathrm{Br}^{-}$ions into an exposed emulsion layer by diffusion. The $\mathrm{Br}^{-}$ions emanated from BR-type layers (emitters) glued to either of the surfaces of the exposed layer that bad been irradiated beforeband with blue-violet lighe. The $\mathrm{Br}^{-}$ion generation and diffusion from the emitters to the exposed

§USF work parially supported by NASA-Ames Researeh Center Grant No. NCC2-521, NASA-MSFC Graat No. NAG8-071 and NASA-ISC Grant No. NAG9-235.

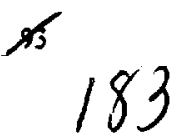


lavers gives rise to a negauve bromine bartier around the latent image centers. thereby increasing the induction periods of deveioping centers. The ability of the centers to be developed depends. then. upon the ratio of the height of the bartier restricuing the arrival of eiectrons at the centers to the depth of the potential well in which the electrons are captured. Thus, controlling the NPE threshold sensitivity is based on different degrees of dispersion of the latent image centers produced by particles with different LET values. The threshold sensivivity of the exposed layer permits only those particle tracks to be developed for which the LET is at least equal to some threshold LET value. Therefore, the technique of finding the planar fluence of the particles with LET $\geq$ LET does not require the track parameters to be measured but is reduced to counting the number of the tracks traversing a paricular section of an NPE surface. Calibration of the tecbnique was achieved by exposing NPEs to particle beams of well-defined LETs.

We used BYa-rype emulsion which permits the integral LET spectra to be measured within an inte:$\mathrm{val}$ from 12 to $\sim 10^{+} \mathrm{MeV} \mathrm{cm}^{-1}$ of biological tissue (water), with the lower limit $\left(\sim 12 \mathrm{MeV} \mathrm{cm}^{-1}\right)$ being defined by the effective sensitivity of the BYa-type emulsion. To obtain a complete LET distribution, we sometimes used the relativistic BR-rype emulsion, thereby making it possible (to within a large microscope scanning error) to find the planar flueace of cosmic radiation particles at smail LET values (the IET of relativiscic protons in tissue is $\simeq 2.0 \mathrm{MeV} \mathrm{cm}^{-1}$. The error in counting these tracks at $L_{E T}=2.0 \mathrm{MeV} \mathrm{cm}_{\text {trob }}=2$ increases (i) due to a bigh urack exposure of the detectors (the satellite fights lasted, as a rule, for more than 10 days) and (ii) because the operator can easily overlook tracks of relativistic protons (low grain densities).

The second technique for finding the LET distributions is based on the use of SSNIDs of the CR-39, $C N$, and polycarionate type, whose effective LET thresholds of track detection are 40,1000, and $2250 \mathrm{MeV} \mathrm{cm}^{-1}$ in water, respectively. CN and Lexan were used in earlier measurements (the ASTP, Skylab, and Apollo 17 missions). During later flights, including the 24 initial tights of the U.S. Shuttle, use was made of SSNTDs of the CR-39, polycarbonate. and polystyrene types which were subjected after the tights to the standard $\mathrm{NaOH}$ etching with $6.25 \mathrm{~N}$ at $70^{\circ} \mathrm{C}$. Preliminary scanning showed that the density

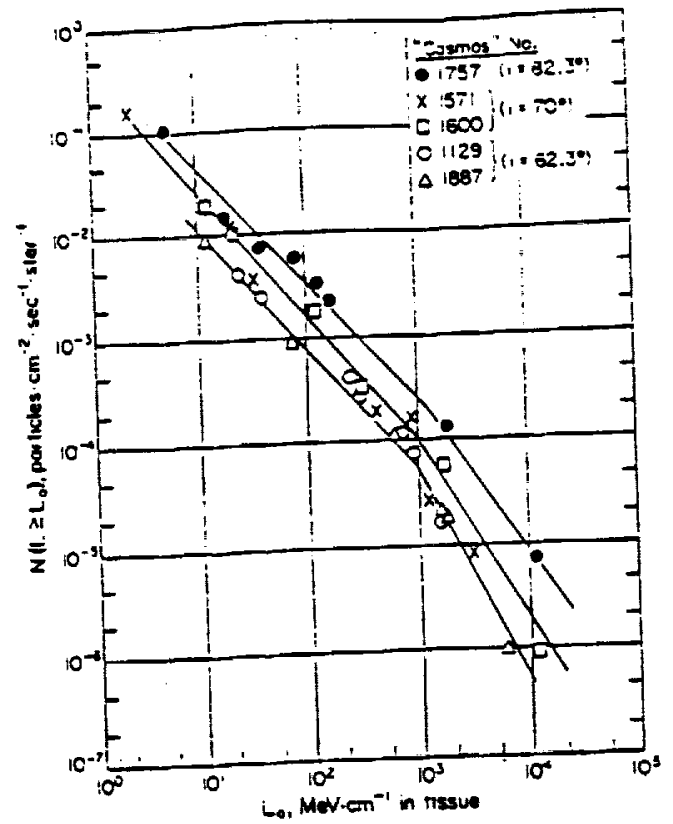

Fic. 1. The experimeataj LET specura obtained from different satellites of the Cosmos series at $\delta \leqslant 1.0 \mathrm{~g} \mathrm{~cm}^{-2}$ by the NPE method.

of the tracks detected in polycarbonate and polyof the wacks very low compared with that of CR-39. The method for using SSNTD to find the IET spectra is descrioed in detail by Henke and Benton (1974).

\section{RESUTTS AND DISCUSSION}

In Fig. I are shown the results of LET spectra measurements by the NPE method. The NPE assemblies were placed in external instrument modules on spacecraft with different orbital parameters (see Table 1). For these external assemblies, the shielding thickness may be considered not to exceed $\sim 1.0 \mathrm{~g} \mathrm{~cm}-1$. The shielding of the detectors by the satellite bodies and by the Earth and the geomerry of the exposures were approximately the same for all of the flights.

The integral LET speetra shown in Fig. I have beed obtained mainly with the BYa-type emulsions, so the distriburion ranged from 12 to $1.5 \times 10^{4} \mathrm{MeV} \mathrm{cm}^{-1}$ of issue. From Fig. $l$ it is seen that the values of the integral spectrum at the lower LET values were

Tabie 1. The flight parameters of the satellites on which the NPE assemblies were

\begin{tabular}{|c|c|c|c|c|}
\hline $\begin{array}{l}\text { Cosmos } \\
\text { series } \\
\text { satellite }\end{array}$ & Exposure time & $\begin{array}{c}\text { Apogee/ } \\
\text { perigee } \\
(\mathrm{km})\end{array}$ & $\begin{array}{c}\begin{array}{c}\text { Orbital } \\
\text { inclioation }\end{array} \\
\end{array}$ & $\begin{array}{l}\text { Solar } \\
\text { acrivity } \\
\text { poriod }\end{array}$ \\
\hline $\begin{array}{l}1129 \\
1571 \\
1600 \\
1757 \\
1887\end{array}$ & $\begin{array}{l}\text { Sep. 25-Oct } 10.1979 \\
\text { Jun. 11-Jun. } 26.1984 \\
\text { Sep. 27-Oce. 10, } 1984 \\
\text { Jun. 11-Jun. 19, } 1986 \\
\text { Sep. 29-Oct. 12. } 198\end{array}$ & $\begin{array}{l}406 / 726 \\
420 / 355 \\
420 / 354 \\
252 / 189 \\
406 / 274\end{array}$ & $\begin{array}{l}62.8^{\circ} \\
70^{\circ} \\
70^{\circ} \\
92.3^{\circ} \\
62.8^{\circ} \\
\end{array}$ & $\begin{array}{l}\max \\
\min \\
\min \\
\min \\
\min \end{array}$ \\
\hline
\end{tabular}




\section{COSMIC RADLATION LET SPECTRA}

obcained using the relacivisuc $B R$-iype fmulsion on board Cosmos 1571 and 1757 only. In orcier to make he presencation of data clear, the experimental poines have beez unined by a solid line of the 3oproximate form $x \cdot L^{-d}$, where $L$ is LET in issue: $I$ and $\beta$ are constants.

The following preliminary conclusions may be drawn from the curves presented in Fig. 1:

(1) experimental values of the integral LEI distriburions are very close to each othe: for the satellites wich similar orbical parameters (Cosmos 1129 and 188\%, Cosmos 1571 and 1600);

(2) effeces of solar acrivity are insignificant (the values of the specura obtained from Cosmos 1129 and 1887 are alike);

(3) slopes of the inregral spectra obtained from sacellites differing in orbit inclination, $i$ are similar to each other (the speciral index $\beta$ of all three spectra for the LEI ranging from 10 to $10^{\mathrm{j}} \mathrm{MeV} \mathrm{cm}^{-1}$ of tissue is the same within deviations of $\pm 15 \%$ );

(4) values of the LET spectra seem to tise with increasing orbit inclinacion ar $i \geq 60^{\circ}$;

(5) the integral LET specarum obtained from Cosmos 1757 is bigher than ail the other spectra despite the fact that the particular orbit was 1.5 times lower in altinde than the ocher orbits.

A preliminary conclusion may be drawn from comparing these results with the resuits of Benton (1983): in the case of bighly inclined orbits $\left(i>60^{\circ}\right.$ ) the absolute flux values of the LET spectra and hence, of the absorbed and equivaleat doses, depend more surongly on the orbit inclination $(i)$ than on altiude $(h)$, whereas in the case of low inclinarion

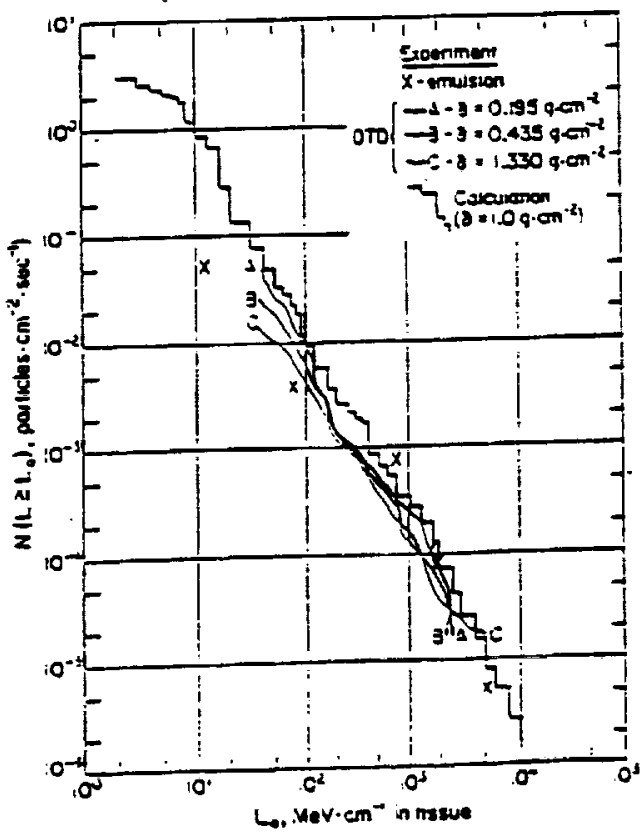

FIG. I The experimeacal and calculated ineegral LET specis obrained from Cosmos 1887 (outside the satedlite) oroits ( $i<60^{\circ}$ ) their jux values depend more strongly on aitiude chan on orbic inclination. Firber measuremears in bigh inclination oroits are aesded for veriñcation.

The oose-ration can be understood by considering how the various contributions to LET vary with orbical alticude and inclinacion. Above $60^{\circ}$ inclinacion at low altimdes galacic cosmic rays dominate the LET. The GCR is aot strongly modulated by altinde at the aititudes considered, bur is modulated by the rigidiry cur-of. which is a iunction of geomagnetic latinude. For lower inclination orbits. trapped parvicles are nore imporanc Irapped paracles are strongly modulated with altitude, but nor so strongly modulated with inclination.

Figures 2 and 3 present the integral LEI spectra oblained from Cosmos 1887 by the NPE and SSITD methods. The respecrive values for the exieral assembties are shown in Fig. 2, while the data obtained inside the sacellite are presented in Fig. 3. The two igures also show the calculated results obcained by the mechod described in Akopova er al. (1987) beinind shielding thickness $\delta=1.0 \mathrm{~g} \mathrm{~cm}{ }^{-2}$ (Fig. 2) and $\delta=1.0,10.0$, and $20.0 \mathrm{~g} \mathrm{~cm}^{-2}$ (Fig. 3). The calculations were made for the Cosmos 1887 orbit par. amerers. The number of bistories is $10^{4}$.

A method for calculating the integral LET spectrum of gaiactic cosmic ray particles is descrioed in Akopova et al. (1987). Our work is the ârst to include both the galacric cosmic ray particies and the radiation beit protons in the region of the South Atanic Anomaly (SAA). The LET distriburions from the protons were determined from the energy specta of adiation belt protons calculated using the Sawyer

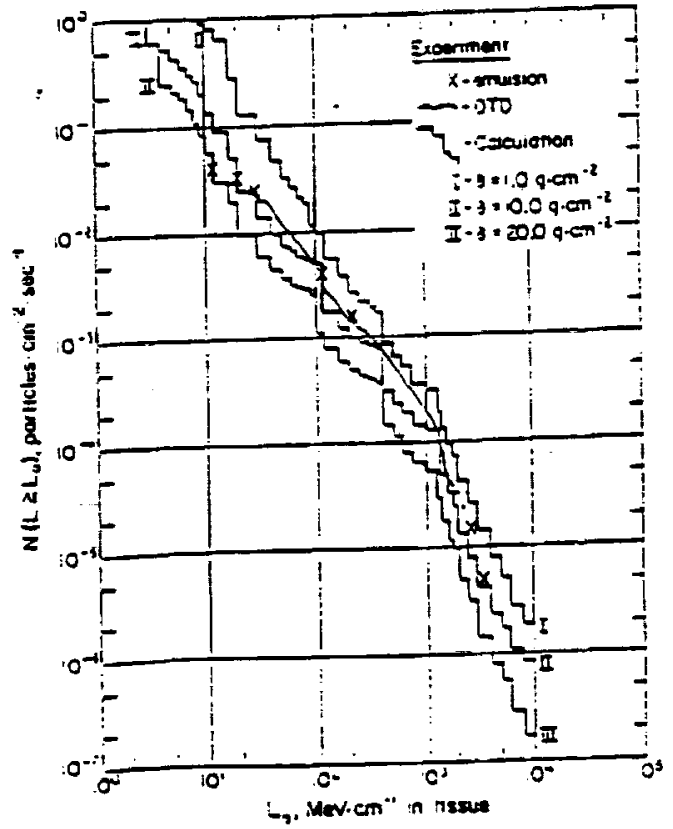

Fic. 3. The experimeatal and enculated integral LET spectr obcained from Cosmos 1887 (inside the sateilite). 185 
and Vette (1976) AP8MIN trapped proton environment. Figures 2 and $:$ present the cotal calculated LET distributions (the histograms).

The following preliminary conclusions may be drawn from analyzing the curves presented in Figs : and 3 .

(1) the experimental results obtained by the NPE and SSNTD methods are similar in the region where the LET spectra overlap. chereby indicating that both metbods may be used in studies of this type. The best agreement between the experiments was obtained from measurements made inside the spacecraft (Fig. 3);

(2) the experimental and calculated data are also in satisfactory agreement with each other. The fac: that the experimental and calculated curves shown in Fig. 3 are about the same at $\delta=10.0 \mathrm{~g} \mathrm{~cm}^{-2} \operatorname{secms}$ to imply that the mean thickness of the shielding of the deteciors was close to $\sim 10.0 \mathrm{~g} \mathrm{~cm}^{-2}$,

(3) it should be noted that the calculated and experimental data disagree at small shielding thicknesses ( $\delta \leqslant 1.0 \mathrm{~g} \mathrm{~cm}^{-2}$ ) especially for the lower LET values (Fig. 2). As shown by a relevant analysis, $85-95 \%$ of the spectrum at the LET values from $\sim 10$ to $100 \mathrm{MeV} \mathrm{cm}^{-1}$ of tissue is due to the radiation belt protons (on assumption of the isotropic proton distribuvion in the SAA). The trapped proton calculations therefore seem to be less consistent with the experiment than the GCR calculations. However, the experimental points are scanty in the given LET range, a fact that should be taken into account in further studies;

(4) the results of calculating the integral LET spectra from galactic cosmic ray paricles behind shielding from 0 to $50 \mathrm{~g} \mathrm{~cm}^{-1}$ were previously done by Heinricin (1977) and Heinrich and Baer (1984), where the following two main conclusions were reached, namely, (i) the specural slopes change at $\sim 10^{3} \mathrm{MeV} \mathrm{cm}^{-1}$ for all shieiding thicknesses and (ii) the spectral slope angle is independent of shielding thickness for LET $>10^{3} \mathrm{MeV} \mathrm{cm}^{-1}$ and depends upon the latter (increases with thickness) for LET $\leqslant 10^{3} \mathrm{MeV} \mathrm{cm}^{-1}$. Our sudies have confirmed the first conclusion completely. Our calculations have shown that the slope angles of the LET spectra are

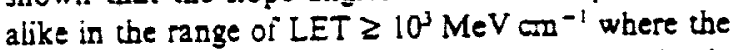
value of the specurum is defined solely by the galactic cosmic ray particles (mainiy, by $F e$ nuclei). The contribution of radiation belt protons to the total integral LET distribution decreases with increasing shieiding thickness. The opposing dependencies lead to the near-independence of the slope angle of the total GCR and proton distributions on shielding for shielding thicknesses up to at least $20 \mathrm{~g} \mathrm{~cm}^{-2}$. for LET $\leq 10^{3} \mathrm{MeV} \mathrm{cm}^{-1}$.

We have used our experimental and calculated LET distribution data to estimate the mean quality factor (QF) in the Cosmos 1887 orbit behind shieldings of 1.0 and $10 \mathrm{~g} \mathrm{~cm}^{-*}$. This applies to paricles having LET in tissue from 2.0 to $10^{4} \mathrm{MeV} \mathrm{cm}^{-i}$. We used the AE8MN environment (Teague and Vetie, 1972) to calculate the doses from the radiation belt ejectrons in the Cosmos 1887 orbit behind a $1.0 \mathrm{~g} \mathrm{~cm}^{-2}$ shieicing. In the case of $310.0 \mathrm{~g} \mathrm{~cm}^{-2}$ shielding, the electrons were neglected because of their small contribution to the total dose. We have found their $Q F$ to be $1.3 \div 0.2$ and $1.7 \div 0.2$ at 1.0 and $10.0 \mathrm{~g} \mathrm{~cm}^{-3}$, respecrively. These values are in good agreement with the calculated and experimental data published eisewhere (Kovalev et al., 1979: Curis et al., 1986).

In future studies, particular attention should be paid to detection of spectra at small LET values. In addition. knowing the distribution of the spacecraft shielding is extremely important, as this information will allow a more correct comparison berween the calculated and experimental data.

\section{REFERENCES}

Akopova A. B., Dudkin V. E., Kappov O. N.. Melkumyan L. V.. Potapov Yu V. and Rshtuni Sh. B. (1986) Determination of cosmic radiation characterisrics aboard Salyut-7 orbital station. Nucl. Tracks Radial. Meas. 12 489-491.

Akopova A. B.. Dudkin V. E.. Karpov O. N.. Melkumyan L. V.. Pouapov Yu. V. and Rshtuni Sh. B. (1988) Determination of cosmic radiation characteristics on board Sainut-7 orbital stavion. Kosm. Issied. XXVI. 162-165.

Akopova A. B., Dudkin V. E., Kovalev E. E., Magradze N. V. and Pocapov Yu. V. (1987) Linear energy transier spectra of cosmic radiation aboard Cosmos1129 ariñcial sacellite. Radiat. Prot. Dosim. 18, $153-156$.

Akopova A. B.. Magradze N. V.. Moiseenko A. A. Muradyan S. H. and Ovnanyan K. M. (1983) Method of selective development of thick-layer nuclear emulsions. Preprint EFI-671 (61)-83 of the Yerevan Physical Institute, Yerevan. U.S.S.R.

Akopova A. B., Vikhrov A. I., Dudkin V. E.. Magradze N. V., Moiseenko A. A.. Muradyan A. H.. Ovnanyan K. M. and Potapov Yu. V. (1985) Measuring the linear energy transfer spectra of cosmic radiation aboard the Cosmos-li29 satellite. Rosm. Issied. XXIII. $479-48 !$ !

Benton E. V. (1983) Dosimetse radiation measuremeats in space. Nucl. Tracks Rodiat. Meas. 7, 1.

Benton E. V. (1986) Summary of radiation dosimetry results on U.S. and Soviet mansed spacecraft. XXVI COSPAR Meeting. Toulouse. June July. 1986. COSPAR Pader VII, p. 7.

Curtis S. P.. Atwell W., Beever R. and Hardy A. (1986) Radiation environments and absorbed dose estimations on manned space missions. Adt. Space Res. 6, 269-274.

Heinrich W. (1977) Calculation of LET-spectra of heavy cosmic ray nuelei at various absorbed depths. Radiar. Effects 33, 143-i48.

Heinrich $W$. and Baer \. (1984) The radiation situation in space and its modification by geomagnetic âeid and shieidings. Adt. Space Res. 4, 13j-14?.

Heake R. P. and Benton E. V. (!974) Heavy cosmic ray mezsurement on Apoljo 16 and 17 missions. Results of the HZE Dosimeter Experiment. Universiry of San Francisco. CA 94117 . Technical Repon No. id. 


\section{COSMIC RADLATION LET SPECTRA}

Kovalev E. E. Bryskin V V. Vinogridor Yu. A. Dudkin V. E.. Kozlova S. B.. Mareniny A. M., Marke!ov V. V., Veicdov N. A. Poimpov Yu. V.. Redko V. L. and Hovanskaya A. I. (1979) Mensuring the linear sae:gy uransier spectra oi cosmic radiation on board Cosmos782 saceilice. Kosm. lssted XVII. 634-sj6.

Petrov V. M.. Akatov Yu. A. Kozlova S. B., Markelov V. V.. Redko V. I.. Smireany L N.. Khorsev A. V. and Cheraych I. V. (1975) The soudy of the mdiation eavironment in dear-Earh space. Space Res. 13, 129.
Sawyer D. M. and Veste $f$. T. (1976) A.P.8 uapped proton taviroamente for solar maximum and solas munimum. NSSDSTWDS-A-R and S-i6-76. Nacional Space Science Deca Cealer. NASAliGoddard Space Cencer. Greeabelt. MD.

Teague M. J. and Verte J. T. (1972) The inner ion eiectron model AE-5. NSSDS 72-10. Vacionai Space Scence Dala Cecter. NASA Goddard Space Cencer. Greeabelt. MD. Septeonber 1972 
$=$

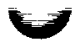

